\title{
Ergonomia do vestuário para idosas entre 60 a 75 anos
}

\section{Ergonomic of clothing- for 60- to 75-year-old women}

\author{
VIANNA, CLAUDIA \\ Laboratório de Ergodesign e Usabilidade de \\ Interfaces da PUC-Rio (LEUI), M.Sc \\ claudiavianna@puc-rio.br \\ QUARESMA, MANUELA \\ Laboratório de Ergodesign e Usabilidade de \\ Interfaces da PUC-Rio (LEUI), D.Sc. \\ mquaresma@puc-rio.b
}

\section{RESUMO}

Segundo o Instituto Brasileiro de Geografia e Estatística (IBGE), em 2000 a população idosa com mais de 60 anos era de 14,5 milhões de pessoas, um aumento de 35,5\% ante os 10,7 milhões em 1991. As revisões feitas pelo IBGE em 2013 mostram que o Brasil se tornara um país idoso em 2029, e em 2018 o número de jovens já caiu em relação ao número de idosos, 63 idosos para cada 100 jovens.

Apesar de todas estas estatísticas e programas para inclusão do idoso, nem todos os aspectos característicos do envelhecimento são considerados no desenvolvimento de produtos de moda, por exemplo. Em se tratando da mulher idosa e sua relação com vestuário, ainda existe uma grande lacuna na oferta mais adequada de roupas para esse público.

Este artigo tem como objetivo constatar que apesar de ser considerado idoso, os indivíduos acima de sessenta anos, ainda são ativos, saudáveis e estão inseridos no mercado de trabalho.

Foram conduzidos grupos de foco com mulheres entre 60 e 75 anos, a fim de levantar as suas opiniões a respeito da oferta atual de produtos de moda. Notou-se que, mesmo dentro desta faixa etária existe diferença entre corpos, mercado e desejos.

idosa, vestuário, corpo, design, ergonomia na moda 


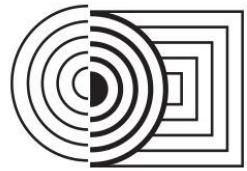

\section{$17^{\circ}$ ERGODESIGN \& USIHC 2019 \\ PUC-Rio, 11 a 13 de dezembro \\ Rio de Janeiro, RJ, Brasil}

$17^{\circ}$ Ergodesign - Congresso Internacional de Ergonomia e Usabilidade de Interfaces Humano Tecnológica: Produto, Informações Ambientes Construídos e Transporte

$17^{\circ}$ USIHC - Congresso Internacional de Ergonomia e Usabilidade de Interfaces Humano Computador

\begin{abstract}
According to the Brazilian Institute of Geography and Statistics (ibge), in 2000 the elderly population over 60 years old was 14.5 million people, an increase of $35.5 \%$ compared to 10.7 million in 1991 . The revisions made by IBGE in 2013 show that Brazil had become an elderly country in 2029, and in 2018 the number of young people has already of yang fallen compared to the number of elderly, 63 elderly for every 100 young people.

Despite all these statistics and programs for the inclusion of the elderly, not all characteristic aspects of agingare considered in the developmentof fashion products, for example. When it comes to the elderly woman and her relationship with clothing, there is still a big gap in the offer of appropriate clothes for this audience.

This article aims to show that despite being considered elderly, individuals over sixty years old, are still active, healthy and are inserted in the job market.

Focus groups were conducted with women aged60 to 75 to raise their views on the current supply of fashiom products. It was noted that even within this age group there a difference between bodies, market and desiresyears old were used. It was noted that even within this age group there is a difference between the bodies, market and desires of clothing participants appropriate.
\end{abstract}

elderly, clothing, body, design, ergonomics in fashion

\title{
1.INTRODUÇÃO
}

Segundo Alves (2018) nas projeções anteriores do IBGE (revisão 2013), o Brasil se tornaria um país idoso em 2029, quando haveria 39,7 milhões de jovens (0-14 anos) e 40,3 milhões de idosos (60 anos e mais). Nesta data, o Índice de Envelhecimento (IE) seria maior do que 100, ou seja, haveria 101,6 idosos para cada 100 jovens. Com as novas projeções (revisão 2018), 0 envelhecimento vai ocorrer um pouco mais tarde, no ano de 2031. No ano 2010, havia 48,1 milhões de jovens de 0 a 14 anos e 20,9 milhões de idosos com 60 anos e mais. O IE era de 43,4 idosos para cada 100 jovens. Em 2018, o número de jovens caiu para 44,5 milhões e o de idosos subiu para 28 milhões, ficando o índice de envelhecimento em 63 idosos para cada 100 jovens.

O governo do Brasil lançou em abril de 2018 a Estratégia Brasil Amigo da Pessoa Idosa. A elaboração dessa iniciativa, que busca alcançar o envelhecimento ativo, saudável, cidadão e sustentável para todos os brasileiros, contou com a colaboração da Organização Pan-Americana da Saúde/Organização Mundial da Saúde (OPAS/OMS).

Com o aumento do percentual de idosos brasileiros, pode-se ressaltar o surgimento de uma nova idosa. Com os avanços da medicina e da tecnologia, e com a conquista de um poder aquisitivo mais estável, essas idosas se apresentam mais ativas e demonstram uma maior participação dentro do âmbito social e profissional. À vista disso, o estilo dessas idosa também se faz importante no contexto das tendências e do mercado da moda. Como aponta Ballstaedt (2007), um novo nicho de mercado está surgindo, com consumidoras que têm comportamentos, estilos de vida e necessidades específicas. Conhecer quais são as demandas dessas idosas no que refere ao vestuário, torna-se relevante para trazer maior conforto, satisfação e segurança a elas.

Inserida na esfera social e profissional, a nova idosa situa-se na faixa etária de 60 a 75 anos. São mulheres que, em decorrência das transformações apresentadas no corpo, como perda da estatura, diminuição da massa óssea e muscular, aumento do peso, entre outras, levam a pensar que não é possível utilizar os mesmos padrões da população adulta na confecção do vestuário das idosas. Para Menezes e Lopes (2009), as idosas prezam não só pelo conforto, como também pelo valor estético da roupa. Apesar da existência de uma vida social ativa nessa faixa etária, e 


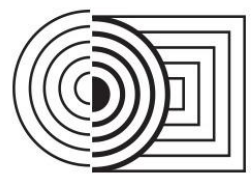

\section{$17^{\circ}$ ERGODESIGN \& USIHC 2019 \\ PUC-Rio, 11 a 13 de dezembro \\ Rio de Janeiro, RJ, Brasil}

$17^{\circ}$ Ergodesign - Congresso Internacional de Ergonomia e Usabilidade

de Interfaces Humano Tecnológica: Produto, Informações Ambientes Construídos e Transporte

$17^{\circ}$ USIHC - Congresso Internacional de Ergonomia e Usabilidade

de Interfaces Humano Computador

de haver demanda do consumo de roupas, ainda não são conhecidas, de fato, as necessidades reais dessas mulheres, as novas idosas, no que diz respeito ao consumo de vestuário

Em relação aos idosos, Menegucci e Santo Filho (2010) sugerem considerar as condições físicas, mentais e psicológicas que envolvem a manipulação deste vestuário, não deixando de incluir as novas tecnologias do setor têxtil, para agregar "conforto e proteção", com a finalidade de melhorar a interface "usuário-roupas-tarefa".

"O número de pesquisas na área de Ergonomia na Moda é ainda muito reduzido, o que justifica a necessidade de uma maior exploração do tema" (PIRES, 2008; CASTILHO e GARCIA, 2001). Constatamos, que o vestuário "pronto para vestir" que existe no mercado não contempla as transformações do corpo da mulher idosa, de acordo com a opinião das novas idosas, em termos de usabilidade, conforto, satisfação e segurança do vestuário.

\section{DESIGN DE MODA}

A moda está ligada ao design, assim como o design à moda. Para Moura (2005), alguns segmentos da moda são voltados para as questões de mercado e gestão de negócios, que não são considerados design. O design estuda as funções, a estética e a função simbólica dos produtos na vida de seus usuários e, segundo Moura (2008, p. 69), "a palavra design está associada à concepção de produto, ao projeto e planejamento [...] desenvolvimento de um projeto que tem como finalidade a realização de um produto". A autora afirma ainda que desenhar faz parte do processo de criação, porém não inclui todo o conceito do processo do design. $O$ design está relacionado ao planejamento, à experimentação, às novas tecnologias, ao mercado e, principalmente, ao usuário. No que concerne ao design de moda, ao se projetar uma peça de vestuário devem ser considerados a modelagem, o tecido, os aviamentos, a função da roupa e todos os processos decorrentes. Moura (2008) ressalta a importância do design em pensar e acompanhar a trajetória de um produto até o seu descarte e/ou sua reutilização.

\section{ERGONOMIA E VESTUÁRIO}

A Ergonomia evidência várias ciências, cujo objetivo é compreender e analisar o relacionamento do ser humano com o trabalho, a tecnologia, o ambiente e os produtos, a fim de desenvolver soluções que proporcionam conforto, satisfação e segurança nessas interações. $O$ estudo ergonômico deve estar presente em diversos setores que se relacionam com seres humanos, não esquecendo dos aspectos físicos, cognitivos e organizacionais envolvidos. Portanto, 0 vestuário pode ser incluído tanto na categoria de proteção do corpo, como para designar o status de um indivíduo na sociedade.

Segundo Saltzman (2008) e Strada (2008), as roupas devem ser criadas respeitando o contato com a pele e o movimento do corpo. Para a autora, a roupa não é só estética: é preciso sentir prazer ao vesti-la, “[...] configurando um guarda-roupa 'básico' e articulado [...] (STRADA, 2008, p. 123).

Na relação ergonomia e vestuário, deve-se levar em consideração a antropometria, que, segundo Dul e Weerdmeester (2004), trata do estudo das dimensões e proporções do corpo humano. A modelagem correta permite a mobilidade do corpo e o bom caimento da peça, já a usabilidade, o conforto e a segurança, aliados aos materiais utilizados, possibilitam a satisfação e o bem-estar dos usuários em relação à roupa. 
$\mathrm{Na}$ relação corpo e modelagem, a antropometria contribui com as medidas do corpo auxiliando na modelagem mais adequada a determinados grupos de usuários. Para Bittencourt (2011), é preciso considerar as diferenças entre os indivíduos e grupos sociais para que as medidas do corpo sejam adequadas ao projeto a ser desenvolvido. As dimensões humanas são de grande importância, portanto, as variações extremas devem ser consideradas, "[...] inclusive como o decréscimo em função da idade em ambos os sexos, após a maturidade do corpo humano" (BITTENCOURT, 2011, p. 106). Na Figura 1, percebe-se as alterações nos corpos conforme 0 avanço da idade, como a curvatura da coluna - o que causa uma má postura -, o aumento do abdômen e a diminuição da altura, do busto e dos glúteos.

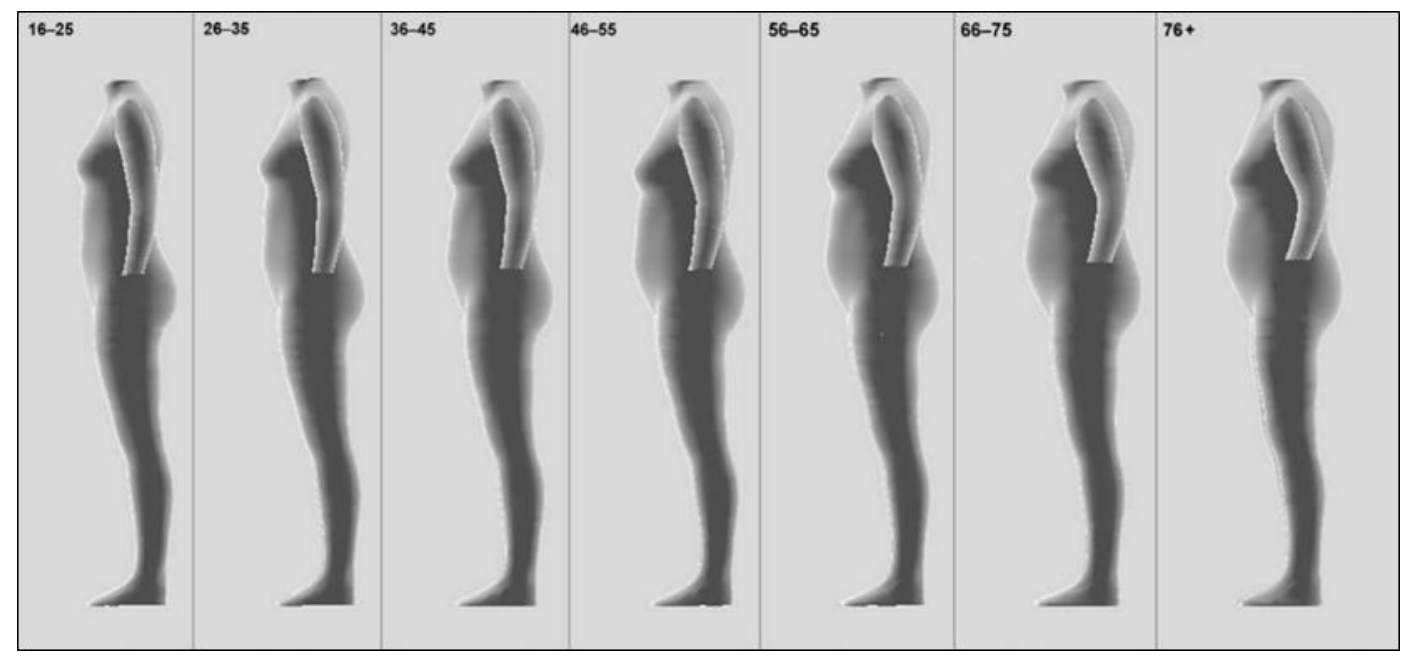

Figura 1 - Perfis de mulheres de sete grupos de idade. Fonte: MCCANN e BRYSON (2014, p. 152).

\section{USABILIDADE DA ROUPA}

Para Moraes (2005), o conceito de usabilidade é quando o produto é adequado ao desempenho da tarefa à qual se destina, facilitando o seu uso em qualquer ambiente. Já lida (2005) menciona a usabilidade quando os produtos se tornam fáceis de entender e de operar, não levando o usuário a erros.

A importância da usabilidade na ergonomia segundo Martins (2005) está na avaliação produtousuário. A sua relevância para o desenvolvimento, a aquisição e o uso dos produtos está no fato de acomodar as necessidades e as características do consumidor. A autora propõe uma metodologia para a avaliação da usabilidade dos produtos de vestuário, considerando indicadores de conforto como uma das principais variáveis para o projeto. Segundo ela, nem todos os produtos de vestuário trazem conforto ao entrar em contato com o corpo e, para avaliar a usabilidade das roupas, a autora utiliza critérios como: facilidade de manejo, de manutenção e de assimilação (clareza no manuseio); segurança; e conforto. Na categoria conforto, só foi utilizado o conforto físico .

Para RUSSO e MORAES, (2005), quando se referem à usabilidade do vestuário, a roupa deve ser fácil de ser usada, ser confortável, e facilitar os movimentos do usuário na execução de tarefas. As autoras citam a satisfação como um dos itens mais importantes da usabilidade, 


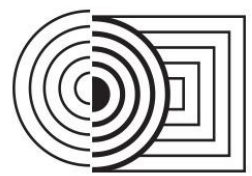

\section{$17^{\circ}$ ERGODESIGN \& USIHC 2019 \\ PUC-Rio, 11 a 13 de dezembro \\ Rio de Janeiro, RJ, Brasil}

$17^{\circ}$ Ergodesign - Congresso Internacional de Ergonomia e Usabilidade de Interfaces Humano Tecnológica: Produto, Informações Ambientes Construídos e Transporte

$17^{\circ}$ USIHC - Congresso Internacional de Ergonomia e Usabilidade

de Interfaces Humano Computador

definindo a relação do usuário com o produto. A satisfação está relacionada com o conforto e com a aceitação do produto (modelagem, tecido, estética).

A usabilidade aplicada ao vestuário engloba vários aspectos. A facilidade em vestir e desvestir uma roupa depende dos acessórios e aviamentos usados. Essas ações devem ser de fácil realização e entendimento, para não constranger o usuário, e devem ser de fácil manejo na forma de abrir, fechar e amarrar. Na questão da manutenção da roupa, a ação deve ser de fácil entendimento, com tecidos com facilidade de lavar e secar. Os produtos de vestuário também devem trazer segurança em relação ao manuseio e não causar desconforto térmico e umidade inadequada, ou apresentar aviamentos que possam irritar a pele, o que pode afetar a saúde e o conforto do usuário.

\section{CONFORTO E SEGURANÇA}

A relação do usuário com o vestuário não deve ser apenas técnica. Gonçalves e Lopes (2007) afirmam que o conforto e a estética são aspectos inerentes à qualidade do produto, sendo cada vez mais exigidos pela demanda do mercado. O conceito de conforto está, em geral, associado ao ambiente térmico. Em relação ao vestuário, pode ser verificada "[...] a resistência térmica, a resistência ao vapor de água, as condições climáticas e o nível de atividade física do indivíduo" (BROEGA e SILVA, 2007, p. 3).

O conforto térmico tem relação com as sensações de calor e frio, exigindo tecidos que proporcionem a satisfação por meio de suas características naturais ou tecnológicas, como os fios de superfícies irregulares que facilitam a circulação do ar. Em relação aos idosos, por não serem tão ativos quanto os jovens, as sensações térmicas são bem distintas tanto no calor como no frio. O conforto sensorial de "toque" está relacionado com a maciez do tecido, que é resultado da sua composição. Segundo Broega e Silva (2007), quando o toque do tecido incomoda o usuário, este não chega a perceber os outros requisitos de conforto como o caimento, a estrutura e os acabamentos da peça.

Pelo fato de o idoso ter a pele mais ressecada, a sensação do tecido em contato com a pele é fundamental para a sua usabilidade, podendo evitar irritações na pele. Em relação ao conforto psico-estético, o idoso perceberá o tipo de material têxtil, a conformação da roupa ao corpo, a escolha das cores e também o odor das roupas usadas. Já o conforto ergonômico engloba todas as sensações acima que, agregadas à modelagem e à confecção adequadas do vestuário e à nova configuração do corpo do idoso, proporcionam o bem-estar e a liberdade dos movimentos. Além disso, devem ser utilizadas tabelas antropométricas atualizadas e próprias para o público que se quer alcançar.

O conforto se relaciona com o usuário nas questões da modelagem, do modelo estético da roupa, dos aspectos ergonômicos de vestir e desvestir, e do tecido apropriado às necessidades, principalmente para os idosos. De acordo com Bartels apud McCann e Bryson (2014), as roupas devem ter conforto, controle da umidade, conforto ergonômico (facilidade de movimento e de ajuste próprio) e conforto psicológico (aparência, ou estar na moda). Os mais idosos que cresceram vestindo fibras naturais, muitas vezes, continuam preferindo-as em detrimento das fibras sintéticas. Os requisitos de conforto, ajuste, desempenho, durabilidade e facilidade de cuidados especiais são necessários para todos os consumidores, em especial os da terceira idade.

As peças de vestuário também devem trazer segurança, os usuários devem ser protegidos contra riscos e danos. O designer deve ser criterioso na escolha dos aviamentos e dos tecidos, e deve 


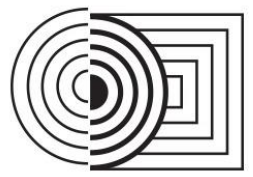

\section{$17^{\circ}$ ERGODESIGN \& USIHC 2019 \\ PUC-Rio, 11 a 13 de dezembro \\ Rio de Janeiro, RJ, Brasil}

$17^{\circ}$ Ergodesign - Congresso Internacional de Ergonomia e Usabilidade de Interfaces Humano Tecnológica: Produto, Informações Ambientes Construídos e Transporte

$17^{\circ}$ USIHC - Congresso Internacional de Ergonomia e Usabilidade

de Interfaces Humano Computador

pensar a modelagem correta para a ocasião em que a roupa será usada, permitindo a mobilidade necessária. Segundo Martins (2005), as propriedades ergonômicas de segurança devem ser verificadas nos aviamentos, sem bordas vivas; no tipo de tecido, não inflamável; nas partes da roupa, como cós, punhos e golas, para que não prejudiquem a circulação; em tecidos que permitam transpiração e ainda nos que têm resistência a fungos, bactérias e umidade.

\section{SATISFAÇÃO COM O USUÁRIO}

Segundo Russo e Hekkert (2008), a relação física dos produtos com o usuário deve ser prazerosa, pois o contato tátil com o material e a forma produzirão a satisfação e o desejo pelo produto. Portanto, pode-se relacionar essa afirmação com os produtos de vestuário em que 0 material e a estética levarão os usuários à satisfação.

A satisfação dos usuários com os produtos de moda está relacionada com a usabilidade, o conforto e a estética da roupa. As características estéticas, o caimento e a forma como a roupa se encaixa no corpo estão relacionados com os materiais utilizados, com a composição têxtil, o conforto, a durabilidade e a manutenção da roupa. Se o produto cumpre sua função, como proteção e aquecimento, se possibilita os movimentos nas tarefas realizadas, agregando usabilidade, conforto e estética, consequentemente proporcionarão a sensação de satisfação aos usuários.

Cabe aos designers de moda considerar nos processos de desenvolvimento dos produtos a funcionalidade, a usabilidade e a satisfação. Segundo Van der Linden (2007), se a funcionalidade não for atendida, talvez o produto não seja usável, portanto se não atende à função, pode causar insatisfação. Além de serem funcionais, os usuários almejam que os produtos proporcionem: usabilidade, sejam fáceis de usar e agreguem estética. O autor ressalta que "[...] a facilidade de uso pode gerar maior satisfação" (VAN DER LINDEN, 2007, p. 61), estreitando a relação entre prazer e usabilidade.

\section{METODOLOGIA}

A metodologia adotada nesta pesquisa foi de cunho qualitativo, que se caracteriza, segundo Dias (2000), basicamente, por uma pesquisa que trata de informações mais subjetivas sobre um determinado fenômeno, e não apresenta medidas numéricas e análises estatísticas. Os métodos e técnicas utilizados nesta pesquisa foram: a revisão bibliográfica, grupos de foco com idosas de 60 a 75 anos.

O grupo de foco é uma técnica utilizada com pequenos grupos de pessoas reunidas para avaliar e identificar problemas comuns ou divergentes dos participantes do grupo. O objetivo do grupo de foco é ouvir os participantes para obter informações dos usuários em relação aos produtos. Cabe ressaltar que não existe um número ideal para a formação dos grupos, entretanto, alguns autores definem a quantidade de participantes que consideram suficiente "Por um lado, Krueger e Casey (2000) afirmam que o tamanho ideal de participantes de um grupo focal varia de seis a oito participantes. Por outro, Morgan e Spanish (1984) indicam que o grupo deve ser de quatro a dez pessoas. Hair et al. (2007) defendem que o ideal é haver entre oito e doze pessoas e, por último, Gomes e Barbosa (2009) acreditam que o ideal é de cinco a doze participantes. (MUNARETTO et al., 2013, p. 17)

Para a condução do grupo de foco com mulheres idosas, foram selecionadas algumas imagens de produtos de vestuário que pudessem promover a discussão entre elas, sobre suas opiniões, necessidades e desejos. As escolhas das imagens expostas ao grupo de foco foram baseadas 
nas pesquisas de Haffenden e Smith (2014), Reich e Otten (1991), Ichards (1881), e Guzel (2013 apud MacCann e Bryson, 2014), que relacionaram dificuldades em relação à usabilidade da roupa. Além dessas pesquisas, outros estudos realizados por diferentes autores - Bartley e Warden, 1962; Shipley e Rosencranz, 1962; Chowdhary, 1997; Goldsberry, Shim e Reich, 1996a; Horne, Campbell e Scholz, 1999; Lee, Damhorst, Kozar e Martin, 2012; Horridge Woodson, 1990 apud Haffenden e Smith, 2014 - mostraram que alguns elementos estéticos não são mais favoráveis às transformações ocorridas no corpo das novas idosas. Alguns dos problemas relatados pelos autores foram: roupas sem manga, decotes muito largos e profundos, utilização de tecidos sintéticos, tecidos que irritam a pele, tipos de fechamento que causam desconforto, como o zíper, para quem tem problemas de artrite, cores não disponíveis nos tamanhos além de os modelos desejados não serem encontrados.

Foram realizadas quatro sessões de grupo de foco. Cada grupo foi formado por quatro mulheres com idades entre 60 a 75 anos, residentes na Zona Sul da cidade do Rio de Janeiro, ativas e inseridas no contexto profissional e social, com a presença do pesquisador responsável e de um pesquisador assistente.

As imagens foram apresentadas em dois tablets, por meio de oito slides contendo cada um uma série de imagens numeradas - para facilitar a identificação e registro da peça - de segmentos diferentes do vestuário, como: blusas, casacos/blazer, saias, vestidos, calças, bermudas/shorts, roupas de praia e estampas.

No primeiro slide (Figura 2), foram expostas imagens de blusa com manga curta, manga comprida e sem manga, com diversos tipos de decotes como: decote em $\mathrm{V}$, decote no lugar, decote em $\mathrm{U}$ e decote canoa, além de babados, drapeados, pregas e laços, em tecidos variados. Com bases em pesquisas, as mulheres mais velhas preferem blusas com manga e sem decotes profundos.

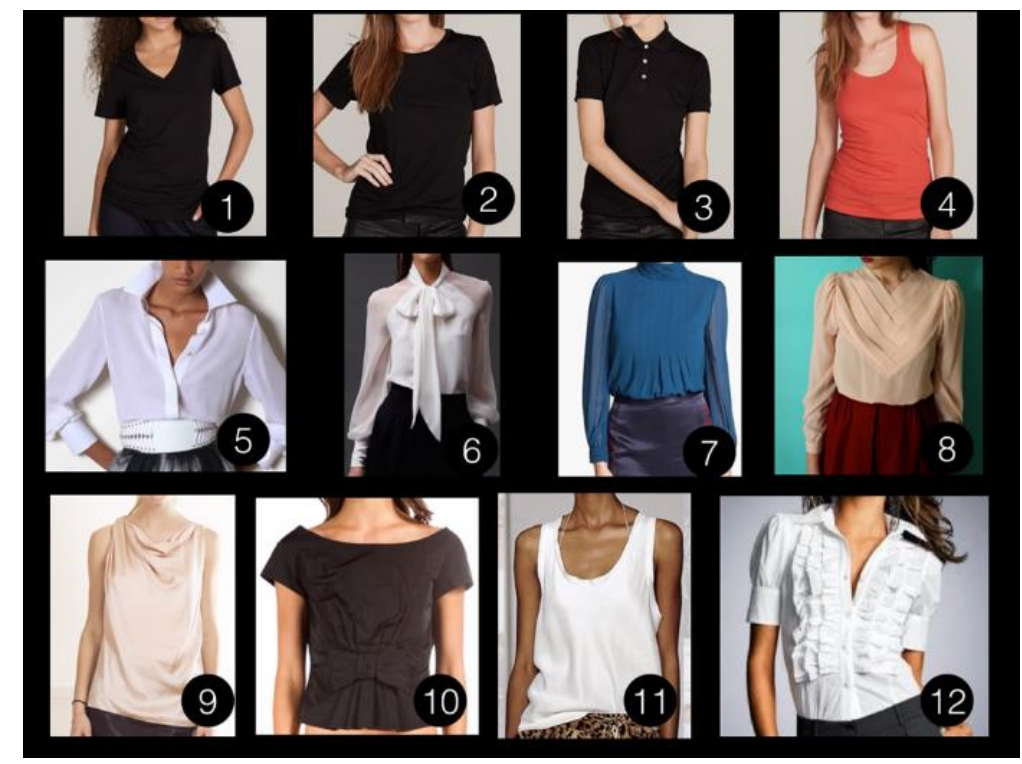

Figura 2 - Tipos de blusas. 
No segundo slide (Figura 3), foram apresentados blazers e casacos de diversos tipos - como spencers, casaco de tricô e de lã, jaqueta de couro, blazers de linho -, além dos diferentes comprimentos de mangas (compridas e três-quartos), e peças com modelagem ou justa ou solta no corpo. As pesquisas mostraram como as mulheres prezam por aspectos da modelagem, do tecido e da funcionalidade da roupa.

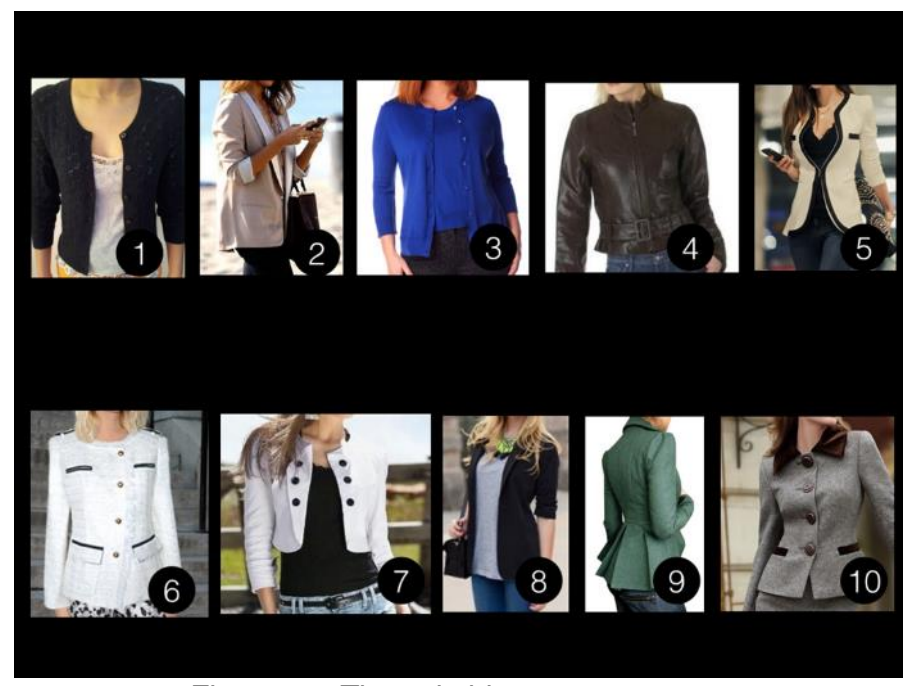

Figura 3 - Tipos de blazers e casacos.

O terceiro slide (Figura 4) mostrava saias em diversos comprimentos: curtas, no joelho e compridas; e em diferentes modelos, como justas, com pregas, plissadas e com fenda. Além disso, foram apresentadas em tecidos distintos, como linho, algodão, couro e seda. $O$ comprimento e o modelo das saias fazem grande diferença em relação ao corpo das novas idosas, por isso a escolha das saias a seguir.

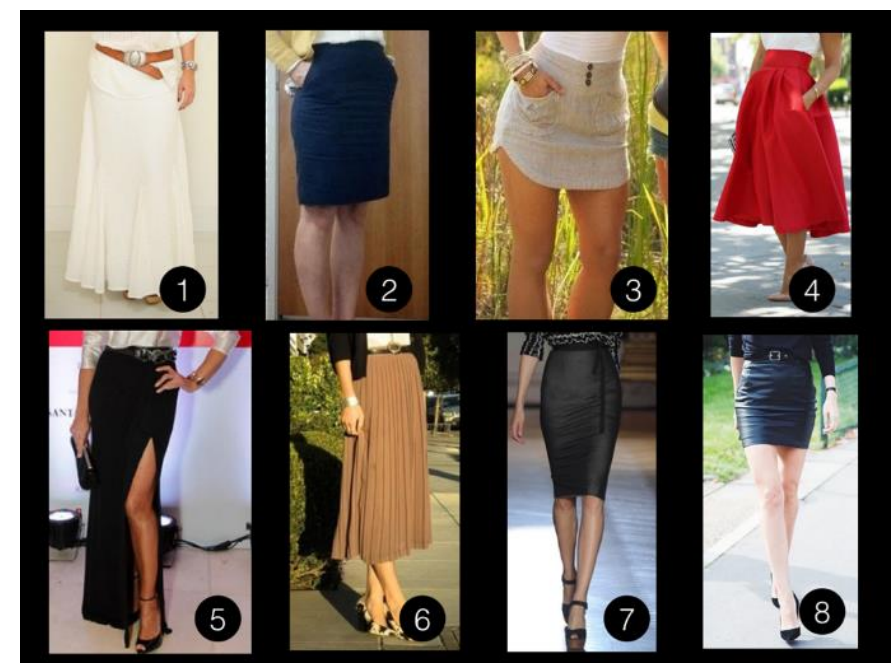


Os vestidos apareceram no quarto slide (Figura 5), em diversas variações: curtos, justos, compridos, no joelho, soltos no corpo, com mangas compridas, três-quartos, curtas ou sem mangas e com alças. Foram apresentados também em tecidos como jeans, linho, seda, malha e voil. A estética, a modelagem e o comprimento é que proporcionarão a satisfação das usuárias em relação às peças.

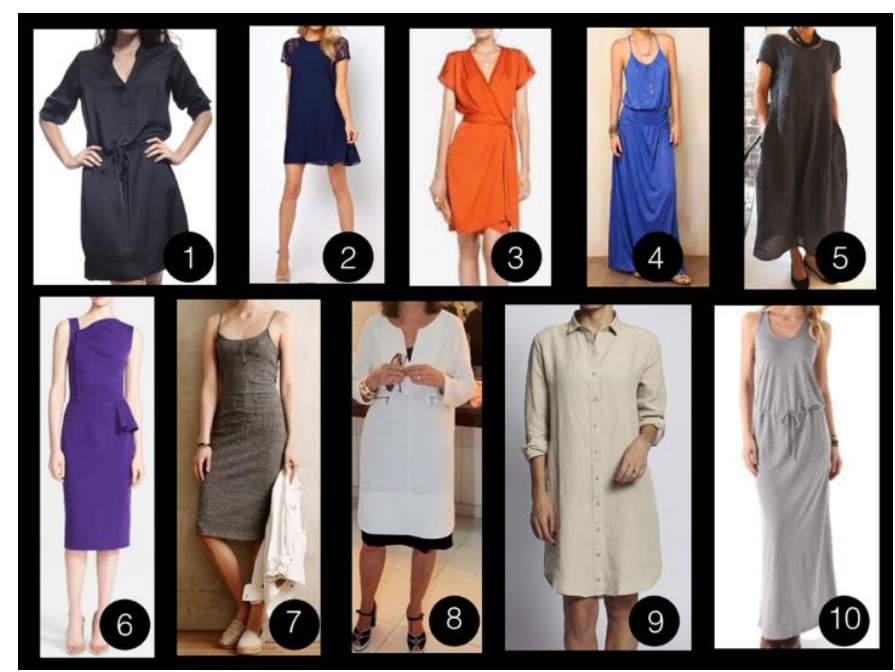

Figura 5 - Tipos de vestidos

No slide com modelos de calças (Figura 6.), foram expostas calças legging, fuseau, pantalona, reta e capri, com cintura alta, no lugar, abaixo do umbigo ou bem abaixo do umbigo, e em vários tipos de tecidos como: linho, jeans, crepe, malha e lã. Também foram escolhidas tanto modelagens mais justas quanto mais soltas, para verificar as questões do conforto e, ainda, a preferência em relação ao zíper e ao elástico e à necessidade de bolsos

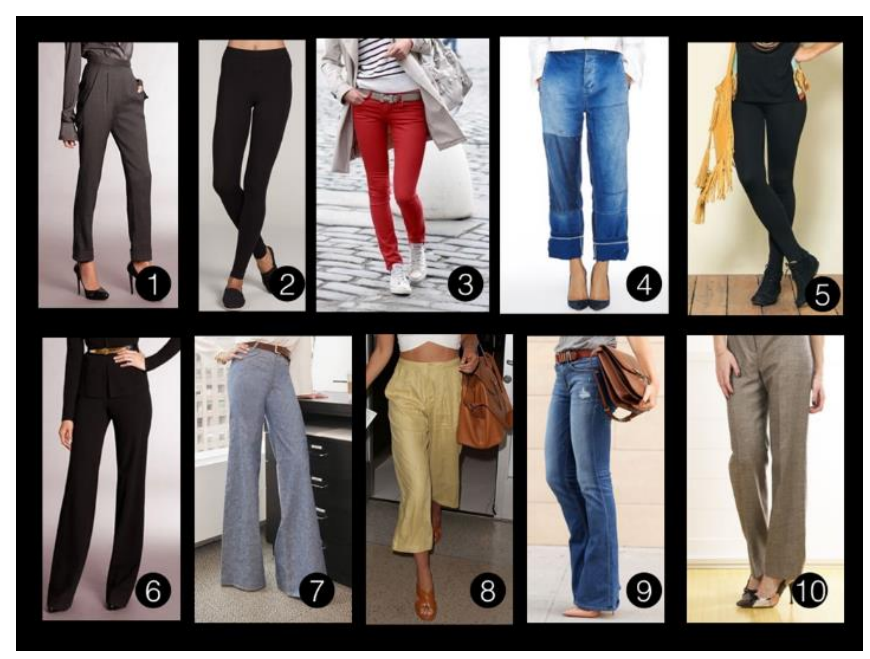

Figura 6 - Tipos de calças 
$17^{\circ}$ ERGODESIGN \& USIHC 2019

PUC-Rio, 11 a 13 de dezembro

Rio de Janeiro, RJ, Brasil $17^{\circ}$ Ergodesign - Congresso Internacional de Ergonomia e Usabilidade de Interfaces Humano Tecnológica: Produto, Informações Ambientes Construídos e Transporte

$17^{\circ}$ USIHC - Congresso Internacional de Ergonomia e Usabilidade

de Interfaces Humano Computador

O sexto slide (Figura 7), teve o propósito de apresentar as bermudas e shorts em diversos comprimentos e tecidos, como jeans e sarja. Não foram encontradas pesquisas referentes ao uso de bermudas e shorts pelas mulheres idosas, porém, como os grupos de foco foram realizadas na Zona Sul da cidade do Rio de Janeiro, é possível que essa peça do vestuário seja usada por grande parte dessas mulheres.

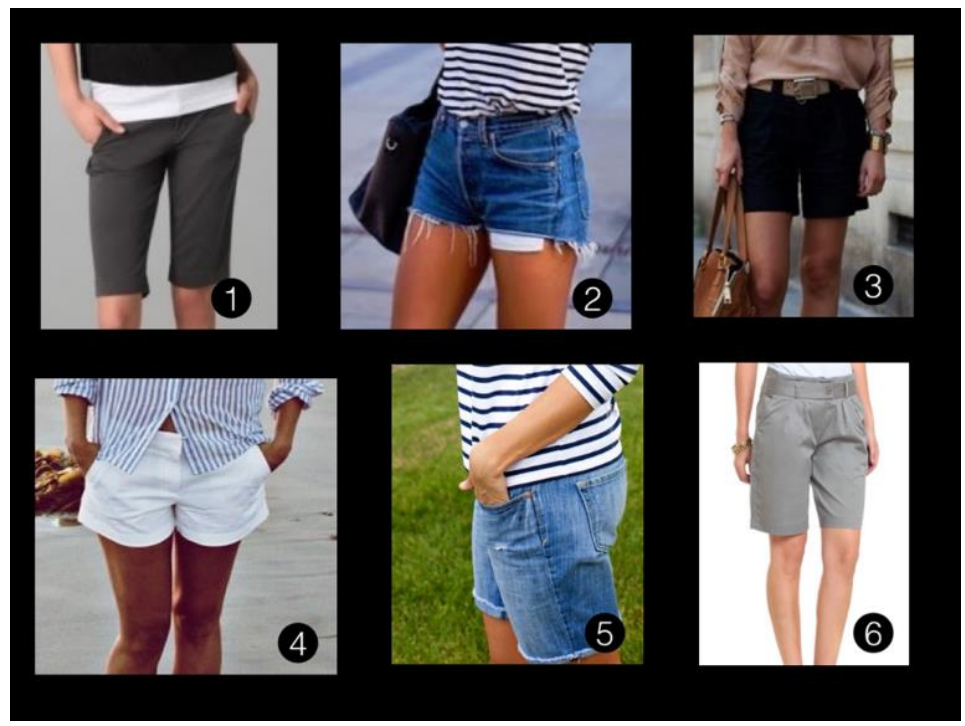

Figura 7 - Tipos de bermudas e shorts.

No sétimo slide (Figura 8), aparecem os maiôs e biquínis, com diferentes tipos de alça, modelos e modelagem. Como mencionado anteriormente em relação ao local de realização da pesquisa, as novas idosas da cidade também frequentam piscinas e praias, onde o uso de roupa própria para banho se faz necessário.

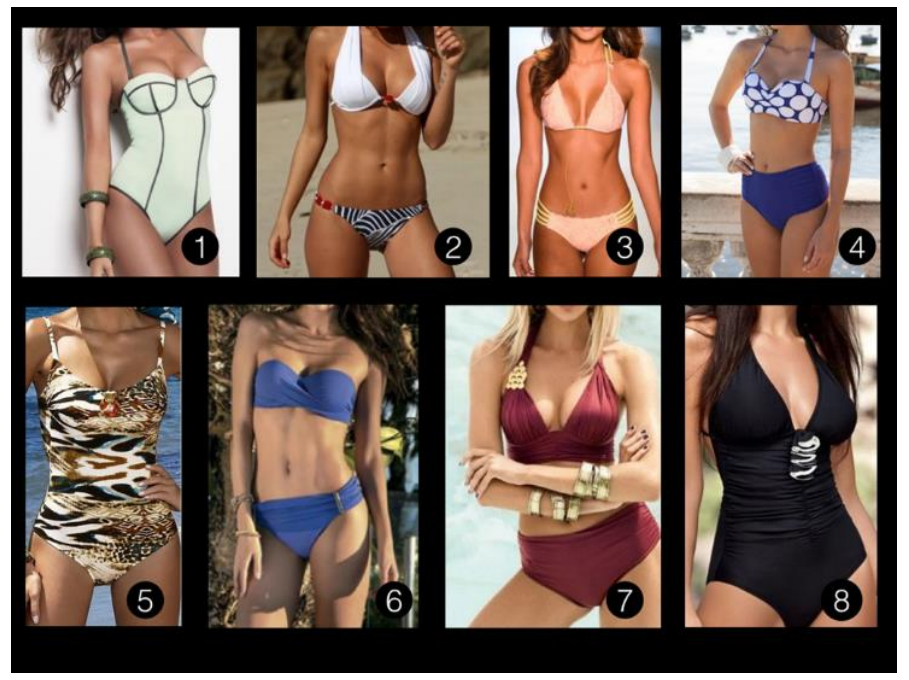

Figura 8 - Tipos de maiôs e biquínis. 
Por fim, em relação às estampas, o último slide (Figura 9) apresenta uma grande variedade: bolas, listras horizontais e verticais, flores, frutas, estampas abstratas, de animais e bordados. Apesar de as estampas estarem cada uma relacionada a uma peça do vestuário, o foco principal foi dado a elas. Com base na pesquisa de materiais, foi constatado que a nova idosa preza pela estética e pelo caimento da roupa, e não deseja se vestir como uma idosa, mas ter opções de escolha no mercado de vestuário pelo que mais a agrada.

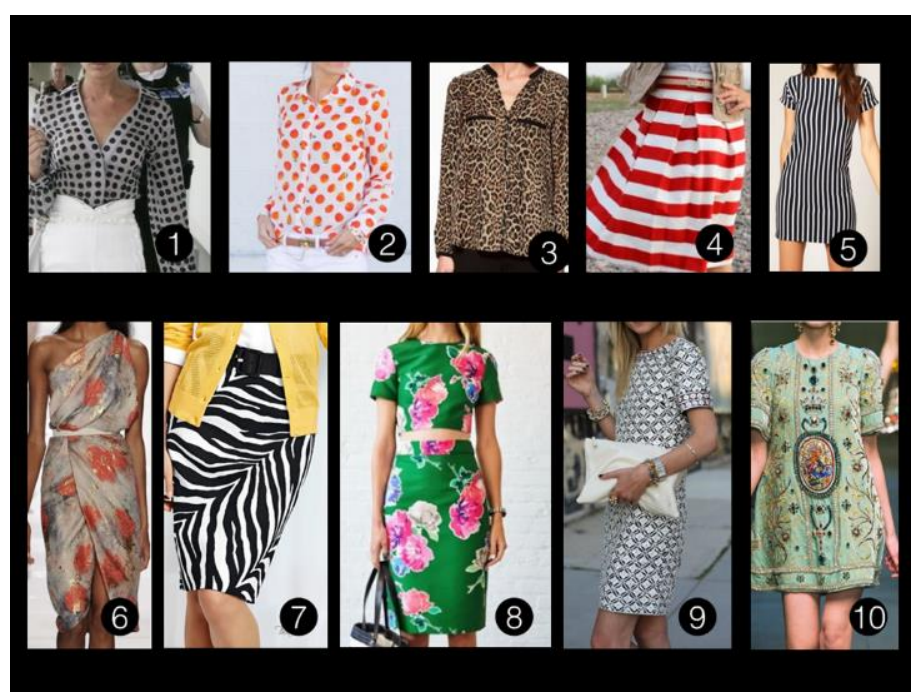

Figura 9- Tipos de estampas.

A duração da sessão de grupo de foco foi de aproximadamente uma hora e vinte minutos. Por meio dessa técnica, foram ouvidas as opiniões das novas idosas no que se refere ao vestuário nas questões de usabilidade, ao conforto, à segurança e à satisfação, com o objetivo de investigar se tais características estavam disponíveis no vestuário oferecido no mercado. A sessão foi gravada em áudio, e observações e comentários foram anotados em um bloco de notas.

\section{ANÁLISE DOS RESULTADOS}

A análise dos resultados obtidos com as técnicas utilizadas nesta pesquisa, como a do grupo focal, possibilitou a aquisição de dados qualitativos que podem servir de base para novos saberes. Nos grupos de foco com as novas idosas foram constatadas as necessidades e as aspirações das participantes em relação ao vestuário.

A análise das roupas apresentadas às participantes dos grupos de foco foi importante para perceber o quanto a modelagem interfere no resultado final do produto vestuário: quando essa modelagem não considera as transformações que ocorrem no corpo da mulher com o passar dos anos, podem prejudicar a usabilidade, o conforto, satisfação e segurança das usuárias com as roupas. Nesses grupos focais também foram expostas as dificuldades das novas idosas em encontrar no mercado modelos esteticamente desejáveis, além de problemas referentes às preferências por diferentes tecidos, especialmente pelos que proporcionam maior conforto e fácil manutenção. 


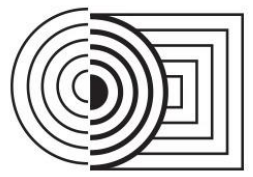

\section{$17^{\circ}$ ERGODESIGN \& USIHC 2019 \\ PUC-Rio, 11 a 13 de dezembro \\ Rio de Janeiro, RJ, Brasil}

$17^{\circ}$ Ergodesign - Congresso Internacional de Ergonomia e Usabilidade de Interfaces Humano Tecnológica: Produto, Informações Ambientes Construídos e Transporte

$17^{\circ}$ USIHC - Congresso Internacional de Ergonomia e Usabilidade de Interfaces Humano Computador

As participantes dos grupos de foco não manifestaram grandes dificuldades no ato de vestir e desvestir as roupas, porém, relataram a dificuldade em vestir roupas com aberturas na parte de trás do corpo. O conforto foi um requisito do qual elas não abrem mão, tanto em relação à modelagem, para não limitar os movimentos, quanto ao tipo de tecido, pelo toque direto com a pele e pela manutenção da roupa. Na questão da segurança, a influência do tecido também foi considerada, uma vez que a pele se torna mais fina e ressecada com o envelhecimento e, consequentemente, é possível que ocorram irritações ou ferimentos. Do ponto de vista da satisfação, as mulheres manifestaram o desejo de usar roupas com bom caimento e de estarem na moda, fatores fundamentais para a autoestima.

Um dos grandes problemas constatados nos grupos de foco foi a questão da numeração das peças de vestuário. As lojas de vestuário utilizam, na sua maioria, tabelas de medidas de padrões oficiais brasileiros, como da ABNT, ou dos estabelecidos pelas próprias marcas, e as participantes não se sentem inseridas nessas métricas. Tal fato resulta na dificuldade de escolher o tamanho ideal, pois além da proporcionalidade do corpo da mulher idosa ser diferente do corpo considerado padrão, os tamanhos diferem de uma marca para a outra. De acordo com as participantes, algumas redes de lojas nacionais nem ao menos oferecem roupas voltadas para 0 público idoso, pois a numeração, por maior que seja, não condiz com o tamanho e as dimensões reais das consumidoras.

As questões referentes à modelagem estão entre as principais queixas das participantes dos grupos de foco. Segundo Frings (2012), para que a modelagem das roupas atenda ao público idoso, é preciso que esse público seja contemplado nas tabelas de medidas. A modelagem feita para uma mulher adulta não corresponde à modelagem que atenda a uma idosa, pelo simples fato de que, com o passar dos anos, várias transformações ocorrem no corpo dessas mulheres.

As blusas e camisas são consideradas uma boa opção para o vestuário das mulheres idosas, por permitirem o uso variado com saias, calças e bermudas. Não foi mencionada uma preferência no modo de vestir e desvestir as blusas, mas foi ressaltado que muitas idosas não se sentem confortáveis com decotes muito próximos ao pescoço, e que elas têm dificuldades em manusear roupas com fecho nas costas. Portanto, é válido inferir que os decotes mais largos e as camisas com botões na parte da frente do corpo sejam melhores de usar. Dependendo da modelagem e do tecido dos casacos, o vestir e desvestir pode interferir no conforto e na segurança das peças.

As calças compridas são um problema no que concerne encontrar a modelagem própria para cada corpo, ou o modelo que as idosas julguem mais adequado à nova faixa etária. A preferência por vestidos foi observada, e todas concordaram que eles são mais fáceis de comprar e vestir do que qualquer outra peça de roupa. Por questões estéticas, as saias não agradam a todas as idosas, pelo fato de não favorecerem determinados tipos de corpos, como as mulheres de estatura mais baixa, ou sem cintura acentuada e com sobrepeso. As bermudas são mais usadas do que os shorts, principalmente pelo fato de que as idosas não querem mais expor as pernas, visto a perda do tônus e o surgimento de varizes. As participantes elegeram o maiô como a nova roupa de praia para essa idade, com poucas exceções de mulheres que julgam ainda poderem usar biquínis e se sentirem confortáveis com duas peças.

Em relação aos tecidos, podemos concluir que as novas idosas preferem tecidos com toque agradável, conforto térmico, de fácil manutenção e com elastano na composição. Já as padronagens como listras verticais - por afinarem a silhueta -, e as estampas - a depender do motivo e da cor, como pois e alguns tipos de florais -, predominaram como favoritas, assim como as cores neutras, como preto e azul-marinho. Ainda no que diz respeito às cores, as novas idosas 


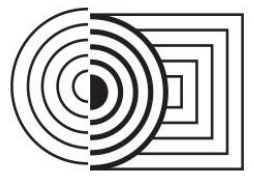

\section{$17^{\circ}$ ERGODESIGN \& USIHC 2019 \\ PUC-Rio, 11 a 13 de dezembro \\ Rio de Janeiro, RJ, Brasil}

$17^{\circ}$ Ergodesign - Congresso Internacional de Ergonomia e Usabilidade de Interfaces Humano Tecnológica: Produto, Informações Ambientes Construídos e Transporte

$17^{\circ}$ USIHC - Congresso Internacional de Ergonomia e Usabilidade

de Interfaces Humano Computador

preferem tons como o preto, pois ajudam a disfarçar o volume do novo corpo, e não gostam da cor bege pela falta de contraste com a pele, por resultar em uma aparência sem expressão.

As observações feitas nos grupos de foco estavam quase sempre relacionadas às transformações do corpo decorrentes do envelhecimento. As participantes justificaram suas escolhas de roupas concentrando-se, principalmente, em aspectos que disfarçam e escondem as imperfeições e as mudanças do corpo. Além disso, foi possível inferir que, muitas vezes, 0 vestuário disponível no mercado não corresponde às expectativas no quesito modelagem e não considera as especificidades da silhueta da mulher idosa.

Com o que foi exposto nos grupos de foco com as novas idosas é possível constatar que houve pontos em comuns e divergentes em relação as peças mostradas. Tem-se como exemplo o fato dos grupos terem sido feitos com mulheres de 60 a 75 anos, mas foi constatado que apesar deste grupo ter um pequeno intervalo entre as idades, elas se diferenciam nas escolhas e estilos de roupas. Constatamos que este grupo pode ser divido em dois - idosas de 60 a 68 anos e idosas de 69 a 75 anos. Visto que, o primeiro grupo, apesar de querer conforto e bem-estar, conseguem comprar roupas que valorizam o corpo, ou por razões de estarem em boa forma física, ou por querem estar na moda, mesmo usando algumas peças básicas e clássicas. O segundo grupo, idosas de 69 a 77 anos, prezam muito mais o conforto, mas com uma estética agradável.

Quanto às características das peças, a maioria das idosas afirmou não usar mais blusas e vestidos sem mangas, mas uma outra parte procura estas blusas no verão. A preferência por roupas que sejam fáceis de vestir e desvestir foi unânime entre as participantes dos grupos,

Em relação aos modelos de roupas, as idosas tendem a preferir roupas atemporais e clássicas. As novas idosas elegeram como favoritos os tecidos de melhor qualidade, com toque agradável, bom caimento e de fácil manutenção. Sobre as calças compridas mais justas no corpo, foram mencionadas, nos grupos de foco, que só são usadas com camisas ou blusas mais compridas, e por cima das calças. Outro ponto observado nos grupos em comum citado foi o de que as mulheres mais velhas procuram roupas que as rejuvenesçam e, apesar de gostarem da variação de cores das coleções, as idosas acabam levando, na maioria das vezes, as peças na cor preta.

Em síntese, constata-se que há divergências cruciais entre as observações das novas idosas e as marcas, especialmente no que concerne à modelagem, às tabelas de medida e à numeração das roupas. De certa forma, as transformações do corpo da mulher idosa ainda não são plenamente consideradas pelos estilistas e designers de moda.

\section{CONCLUSÃO}

Como a moda e o processo de construção do vestuário estão em constantes transformações, essa evolução deve se adaptar às mudanças sociais, culturais, industriais e mercadológicas, democratizando 0 ato de vestir. Com a diversidade de materiais e técnicas, somada a uma produção cada vez mais rápida e eficiente, torna-se possível agradar e satisfazer a maior quantidade de usuários. Porém, as modelagens das roupas, muitas vezes sem parâmetros de numeração ou proporção, existentes no Brasil, não contemplam o corpo do idoso, e, especialmente para o propósito desta pesquisa, o corpo da nova idosa.

Os princípios ergonômicos devem ser empregados em todas as etapas do projeto de construção do vestuário. Na relação ergonomia e vestuário, deve-se levar em consideração a antropometria, que trata do estudo das dimensões e proporções do corpo humano. Uma boa modelagem, com medidas corretas, permite a mobilidade do corpo e o bom caimento da roupa, proporcionando 
conforto e segurança. A satisfação e o bem-estar dos usuários dependem dos materiais usados na confecção e da usabilidade. A usabilidade aplicada ao vestuário envolve vários aspectos, desde a facilidade em vestir e desvestir - e entendimento da peça em si, a fim de não constranger o usuário - até a questão da manutenção da roupa, que deve ser confeccionada com tecidos que sejam fáceis de lavar, secar e passar. Além disso, o vestuário deve proporcionar segurança no que concerne ao manuseio, não causar desconforto térmico e umidade inadequada, e não apresentar aviamentos que possam irritar a pele, o que afeta a saúde e o conforto do usuário, principalmente dos idosos.

Por meio de grupos de foco com mulheres de 60 a 75 anos de idade, foi possível constatar a influência das transformações do corpo nas escolhas de vestuário. Foram observadas a dificuldade da nova idosa em relação às roupas disponíveis no mercado e também as questões de usabilidade, conforto, satisfação e segurança do vestuário. Por fim, foi verificado que o mercado não oferece opções de moda de acordo com o desejo e as expectativas das usuárias idosas. Um dos grandes resultados desta pesquisa foi constatar que dentro deste grupo de idosos de 60 a 75 anos, surgem subgrupos bem distintos, com demandas diferentes, tanto na usabilidade, no conforto, segurança e no bem-estar dessas usuárias; e também na estética desejada.

\section{REFERÊNCIAS BIBLIOGRÁFICAS}

ASSOCIAÇÃO BRASILEIRA DE NORMAS TÉCNICAS. NBR 13377: Medidas do corpo humano para vestuário - Padrões referenciais. Rio de Janeiro: ABNT, 1995.

BITTENCOURT, Fábio. Antropometria: Conceitos. In: BITENCOURT, Fábio. (org.) Ergonomia e conforto humano. Rio de Janeiro, Rio Book's, 2011.

BROEGA, Ana Cristina e SILVA, Maria Elisabete Cabeço. O conforto total do vestuário: design para os cinco sentidos. Buenos Aires: $\vee$ Encuentro Latinoamericano de Diseño. "Diseño en Palermo". Universidade de Palermo, 2010.

CASTILHO, Kathia e MARTINS, Marcelo M. Discursos da moda: semiótica, design e corpo. São Paulo: Editora Anhembi Morumbi, 2005.

DIAS, Claudia Augusto. Grupo focal: técnica de coleta de dados em pesquisas qualitativas. Informação \& Sociedade, estudos. 10.2, 2000.

FRINGS, Gini Stephens. Moda: do conceito ao consumidor. Porto Alegre: Bookman, 2012. GONÇALVES, Eliana e LOPES, Luciana Dornbusch. Ergonomia do vestuário: conceito de conforto como valor agregado ao produto de moda. Buenos Aires: II Encuentro Latinoamericano de Diseño. Facultad de Desiño y Comunicación, 2007.

GOVERNO DO BRASIL, Estratégia Brasil Amigo Da Pessoa Idosa. 2018 Disponível em:https://www.paho.org/bra/index.php?option=com_content\&view=article\&id=5625:brasillanca-estrategia-para-melhorar-vida-de-idosos-com-base-em-recomendacoes-daoms\&ltemid=820 Acesso em:08/09/2019

HAFFENDEN, V.; SMITH, J. Designing Base Layers for Apparel for the Active Ageing Population: Balancing Technology and Aesthetics. Textile-led Design for the Active Ageing Population, p. 361, 2014.

IIDA, Itiro. Ergonomia - Projeto e Produção. $2^{\mathrm{a}}$ ed. São Paulo: Edgard Blucher, 2005, 614p. MUNARETTO, Lorimar Francisco et al. Um estudo sobre as características do método Delphi e de grupo focal, como técnicas na obtenção de dados em pesquisas exploratórias. Rev. Adm. UFSM, Santa Maria, v. 6, n. 1, p. 09-24, jan./mar., 2013. 
MARTINS, S.B. O conforto no vestuário: uma interpretação de ergonomia - metodologia para avaliação de usabilidade e conforto no vestuário. Florianópolis: UFSC, Departamento de Engenharia de Produção, 2005. Tese de Doutorado.

McCANN, Jane e BRYSON, David. Textile-led design for the active ageing population. Cambridge: Elsevier, 2014.

MENEGUECCI, Franciele e SANTOS FILHO, Abílio Garcia. Proteção e conforto: a relação entre os tecidos e o design ergonômico do vestuário para idosos. In: Congresso Brasileiro de Pesquisa e Desenvolvimento em Design (9ํㅜ 2010, São Paulo).

MENEZES, Tânia M.de O., LOPES, Regina Lúcia M. e AZEVEDO, Rosana Freitas. A pessoa idosa e o corpo: uma transformação inevitável. Eletrônica de Enfermagem UFG.2009;11(3):598604.Disponívelem:<http://www.fen.ufg.br/revista/v11/n3/v11n3a17.htm>. Acessado em: 27 fev. 2016.

MOURA, Mônica. A moda entre a arte e o design. In: PIRES, Dorotéia Baduy. (org.) Design de moda, olhares diversos. Barueri, São Paulo, Estação das Letras e Cores Editora. 2008. 423p.

MORAES, Anamaria de. Ergodesign de Produto: Agradabilidade, Usabilidade E Antropometria. Rio de Janeiro: IUsEr, 2005.

PIRES, Dorotéia Baduy. (org.) Design de moda, olhares diversos. Barueri, São Paulo, Estação das Letras e Cores Editora. 2008. 423p.

ORGANIZAÇÃO PAN-AMERICANA DA SAÚDE/ORGANIZAÇÃO MUNDIAL DA SAÚDE (OPAS/OMS) OMS divulga metas para 2019; desafios impactam a vida de idosos. 2019.Disponivel em: https://sbgg.org.br/oms-divulga-metas-para-2019-desafios-impactam-avida-de-idosos/ Acesso em 08/09/2019

RUSSO, Beatriz e MORAES, Anamaria de. Usabilidde $\mathbf{x}$ agradabilidade de produtos. In: MORAES, Anamaria de. (org.) Ergodesign de produto: Agradabilidade, usabilidade, segurança e antropometria. Rio de Janeiro, iUsEr, 2005.

RUSSO, Beatriz e HEKKERT, Paul. Sobre um produto: os princípios fundamentais. In MONT'ALVÃO, Claudia e DAMAZIO, Vera. (org). Design ergonomia emoção. Rio de Janeiro, Mauad X, FAPERJ, 2008.

SALTZMAN, Andreia. O design vivo. In: PIRES, Dorotéia Baduy. (org.) Design de moda, olhares diversos. Barueri, São Paulo, Estação das Letras e Cores Editora. 2008. 423p.

STRADA, Nanni. Relatos de uma designer de moda. In: PIRES, Dorotéia Baduy. (org.) Design de moda, olhares diversos. Barueri, São Paulo, Estação das Letras e Cores Editora. 2008. 423p. VANDER DER LINDEN. Ergonomia e design: prazer e risco no uso dos produtos. Porto Alegre, UniRitter Ed., 2007.

\section{AGRADECIMENTOS}

Agradeço a concessão da bolsa de mestrado VRAC do PPGDESIGN da PUC-Rio para o financiamento da pesquisa.

A CAPES, pelo apoio com a bolsa de mestrado.

À PUC-Rio e ao Departamento de Artes \& Design, que contribuíram para que este percurso pudesse ser concluído. 